\title{
Impact of rehabilitation on mortality and readmissions after surgery for hip fracture
}

Dario Tedesco ${ }^{{ }^{*}}$ D , Dino Gibertoni ${ }^{1}$, Paola Rucci ${ }^{1}$, Tina Hernandez-Boussard ${ }^{2}$, Simona Rosa ${ }^{1}$, Luca Bianciardi ${ }^{3}$, Maurizia Rolli ${ }^{3}$ and Maria Pia Fantini ${ }^{1}$

\begin{abstract}
Background: Hip fracture in elderly patients is a rising global public health concern because of population ageing, and increasing frailty. Long-term morbidity related to poor management of hip fracture is associated with decreased quality of life, survival, and increase in healthcare costs. Receiving postoperative rehabilitation is associated with better outcomes and a higher likelihood of returning to pre-existing level of functioning. However little is known about which postoperative rehabilitation pathways are more effective to optimize patient outcomes. Few studies have analyzed postoperative rehabilitation pathways in a universal healthcare system. The aim of this study is to analyze the impact of post-acute rehabilitation pathways on mortality and readmission in elderly patients undergoing surgery for hip fracture in a large metropolitan area in Italy.
\end{abstract}

Methods: In this retrospective cohort study, we analyzed 6-month mortality from admission and 6-month readmission after hospital discharge in patients who underwent surgical repair for hip fracture in the hospitals of the Bologna metropolitan area between 1.1.2013 and 30.6.2014. Data were drawn from the regional hospital discharge records database. Kaplan-Meier estimates and multiple Cox regression were used to analyze mortality as a function of rehabilitation pathways. Multiple logistic regression determined predictors of readmission.

Results: The study population includes 2208 patients, mostly women $(n=1677,76 \%)$, with a median age of 83.8 years. Hospital rehabilitation was provided to 519 patients (23.5\%), 907 (41.1\%) received rehabilitation in private inpatient rehabilitation facilities (IRF) accredited by the National Health System, and 782 (35.4\%) received no post-acute rehabilitation. Compared with patient receiving hospital rehabilitation, the other groups showed significantly higher mortality risks (no rehabilitation, Hazard Ratio $(H R)=2.19,95 \% \mathrm{Cl}=1.54-3.12, p<0.001$; IRF rehabilitation, $\mathrm{HR}=1.66$, $95 \% \mathrm{Cl}=1.54-1.79, p<0.001)$. The risk of readmission did not differ significantly among rehabilitation pathways.

Conclusions: Intensive hospital rehabilitation was significantly associated with a lower risk of mortality compared to IRF rehabilitation and no rehabilitation. Our results may help in the development of evidence-based recommendations aimed to improve resource utilization and quality of care in hip fracture patients. Further research is warranted to investigate the impact of the rehabilitation pathway on other outcomes, such as patients' functional status and quality of life.

Keywords: Hip fracture, Elderly, Rehabilitation, Surgery

\footnotetext{
* Correspondence: dario.tedesco@unibo.it

${ }^{1}$ Department of Biomedical and Neuromotor Sciences, University of Bologna,

Via San Giacomo, 12, 40126 Bologna, Italy

Full list of author information is available at the end of the article
}

(c) The Author(s). 2018 Open Access This article is distributed under the terms of the Creative Commons Attribution 4.0 International License (http://creativecommons.org/licenses/by/4.0/), which permits unrestricted use, distribution, and reproduction in any medium, provided you give appropriate credit to the original author(s) and the source, provide a link to the Creative Commons license, and indicate if changes were made. The Creative Commons Public Domain Dedication waiver (http://creativecommons.org/publicdomain/zero/1.0/) applies to the data made available in this article, unless otherwise stated. 


\section{Background}

Hip fracture in elderly patients is a global public health concern because of its frequency and functional consequences on individuals experiencing this event [1-3]. Population ageing and increasing frailty play an important role in delayed recovery and declining health in this group of patients [4]. Moreover, long-term morbidity related to poor management of hip fracture is associated with decreased quality of life and survival as well as significant increase in healthcare costs [5].

Evidence shows that delivery of surgery in hip fracture patients within $48 \mathrm{~h}$ of admission is associated with significant lower mortality rates [6-8]. International guidelines recommend an early mobilization of the patient on the day after surgery unless contraindicated and a post-acute rehabilitation plan led by a multidisciplinary team including physicians, physical and occupational therapists [9-11]. Receiving postoperative rehabilitation is associated with better outcomes and a higher likelihood of returning to pre-existing level of functioning [12-14]. However, little is known about which postoperative rehabilitation pathways are more effective to optimize patient outcomes and health system characteristics associated with better patient outcomes is scant [15-17]. In addition, to our knowledge few studies have analyzed postoperative rehabilitation pathways in a universal healthcare system [15].

Italy has a universal single-payer health system managed by the state and the regions. The central government oversees the overall system and defines the essential levels of care to be delivered to the citizens, free of charge or after the payment of a fee, with public resources collected through general taxation. The regions are responsible for the actual planning and delivery of services with a certain degree of autonomy $[18,19]$. In the last decade, Emilia-Romagna region has improved the management of patients with hip fracture, issuing policies and guidelines aimed at reducing the delay of surgery and designing specific pathways for postoperative rehabilitation [20]. However, the effect of these programs at the population-level is unknown.

The aim of this study is to analyze the impact of post-acute rehabilitation pathways on mortality and readmission in elderly patients undergoing surgery for hip fracture in the large metropolitan area of Bologna, located in Emilia-Romagna region, Italy.

\section{Methods}

\section{Study design and population}

The data sources for this observational cohort study were the Hospital Discharge Records (HDRs) database of the Emilia-Romagna region (Italy), the mortality registry, the regional domiciliary care database (ADI) and outpatient specialty care database (ASA). We extracted from HDRs data for all patients aged > 64 years with a primary diagnosis of hip fracture (ICD-9-CM codes 820.0-820.9) from hospitals in the Bologna Metropolitan Area, Italy (over 1 million inhabitants and two Local Health Authorities), discharged between January 1, 2013 and June 30, 2014. We selected patients from hospitals with at least 100 procedures per year in order to reduce variations related to caseload, which resulted in the exclusion of 16 hospitals and 188 patients. We included patients who underwent a surgical procedure of total or partial hip replacement (ICD-9-CM codes 81.51-81.52) or the reduction of fracture and dislocation (ICD-9-CM codes 79.0-79.5), which resulted in the exclusion of 106 patients. We excluded patients who died within one day from admission (Fig. 1). For the analysis on readmissions we excluded patients who died during the hospital stay (Fig. 2).

\section{Interventions and outcomes}

We considered the episode of care as the period of time between the admission for hip fracture and the discharge after post-acute inpatient rehabilitation, when provided. Patients were classified into three pathways according to the type of post-acute rehabilitation: 1) hospital rehabilitation, when rehabilitation was provided in the same hospital where patients received the surgical procedure; 2) IRF rehabilitation, when patients were admitted to private inpatient rehabilitation facilities (IRF), accredited by the National Health System, within 2 days from the index stay discharge and no previous post-acute rehabilitation had been performed. IRFs are private facilities that are accredited to provide inpatient post-acute rehabilitation within the National Health System and are reimbursed by the Region on the basis of a daily admission fee. The accreditation implies that IRFs are allowed to operate within the National Health System because they meet specific parameters of effectiveness and efficiency in terms of staff qualification, procedure volumes and quality of care provided.

We set a 2-day threshold for IRF rehabilitation in order to include patients who received inpatient care soon after the index admission. Over $90 \%$ of patients who received out-of-hospital rehabilitation were admitted to IRFs within 2 days from the index discharge; 3) no post-acute rehabilitation.

A small group of patients $(\sim 1 \%)$ who received both hospital and IRF rehabilitation were included in the hospital rehabilitation pathway.

Community rehabilitation was not included in our analysis because it is provided to only $9.6 \%$ of cases after discharge. Moreover, many patients seek private 


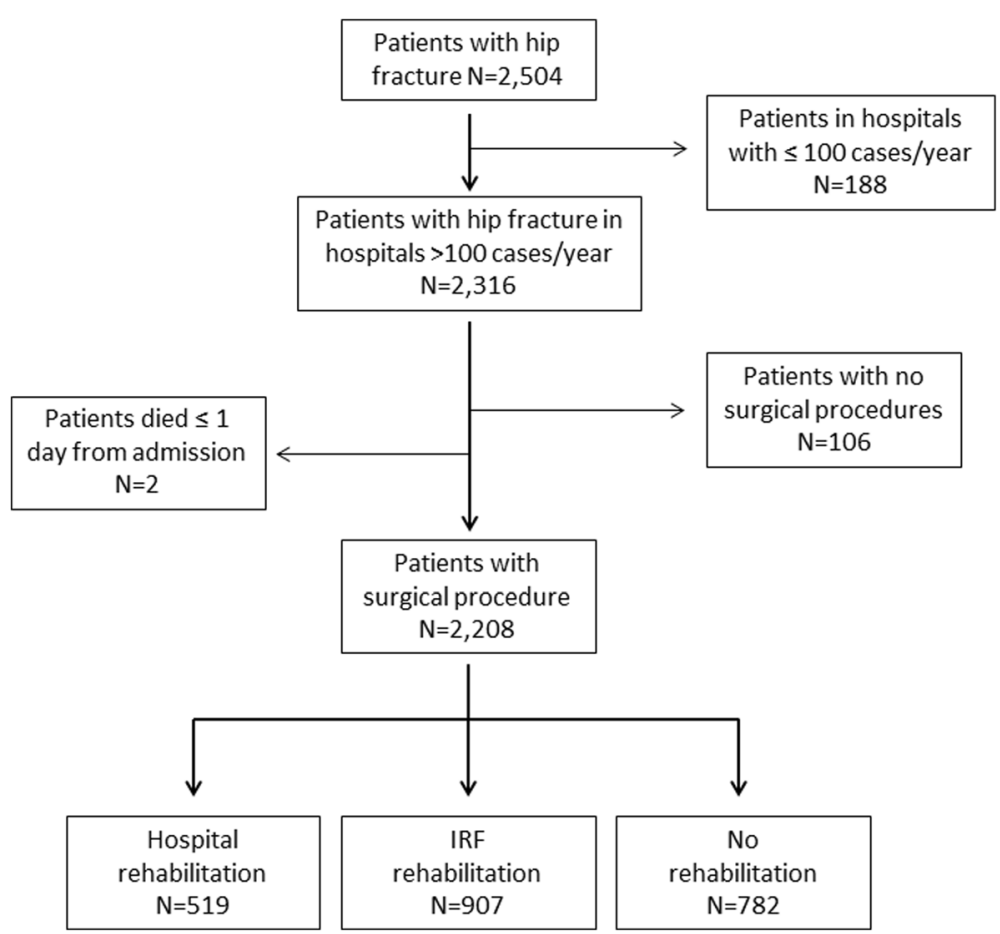

Fig. 1 Flowchart showing patient selection in the study

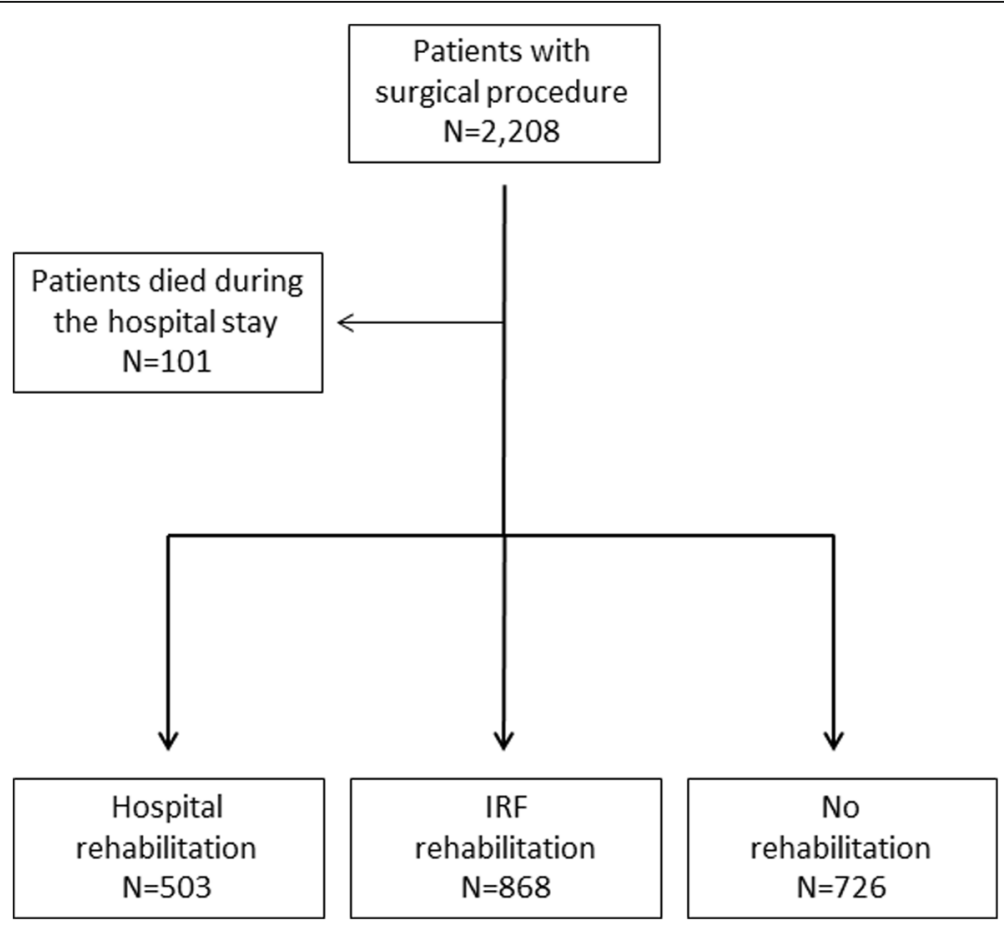

Fig. 2 Flowchart showing patient selection for the analysis on readmissions 
outpatient rehabilitation instead of community rehabilitation.

The outcomes of interest were mortality at 6 months from index admission, all-cause readmission, and orthopedic readmissions within 6 months from index discharge, in line with other studies [21-24].

Patients' socio-demographic characteristics (age and gender) and comorbidity were also retrieved from hospital discharge records. Specifically, the presence or absence of myocardial infarction, heart failure, peripheral vascular disease, cerebrovascular disease, dementia, hypertension, neurological disease and renal disease was searched in the 2 years preceding the index admission using Elixhauser et al. algorithm [25]. The total number of comorbidities was also calculated. We used domiciliary care in the 6 months prior to the index stay as a proxy of patient frailty. Variables related to the admission included length of stay (LOS) from admission to discharge, including the hospital rehabilitation period, time to surgery ( $\leq 48 \mathrm{~h},>48 \mathrm{~h}$ ), type of surgical procedure (reduction versus hip replacement), polytrauma (yes/ no), open fracture (yes/no).

\section{Statistical analysis}

$X^{2}$ and Kruskal-Wallis tests were used to compare patient characteristics among the three pathways. Following significant tests, post-hoc pairwise comparisons were performed at a Bonferroni-corrected significance level of $0.017(0.05 / 3)$. Six-month mortality was estimated using Kaplan-Meier analysis and compared among rehabilitation pathways using log-rank test for the overall six-month period and then distinguishing the first 30-day period from the 31-180 day period. This was done to take into account the expectation that the majority of mortality events occur in the first month after admission. Multiple Cox regression was used to estimate the mortality risk in the rehabilitation pathways, adjusted for patients' age, gender, comorbidities and intervention characteristics. The risk of all-cause and orthopedic readmission at 6 months in the three pathways, adjusted for the same set of covariates listed above, was estimated using multiple logistic regression models. In those models, the non-independence of patients within hospitals was taken into account by calculating robust standard errors adjusted for the patient-hospital clusterisation. Both in the Cox regression and in the logistic regression, a backward stepwise procedure was used to remove non-significant predictors until a parsimonious model including only significant covariates was achieved. Stata v.13.1 was used for all analyses.

\section{Results}

Table 1 shows the characteristics of study patients, that included predominantly females and had a mean age of 84 years. Of the 2208 patients analyzed, 907, 41.1\% received IRF rehabilitation, 519 (23.5\%) hospital rehabilitation and $782(35.4 \%)$ did not receive post-acute rehabilitation. The three groups did not differ significantly on age $(p=0.055)$ and gender $(p=$ 0.542). Patients receiving hospital rehabilitation showed on average more comorbidities (3.4 vs. 2.1 for IRF rehabilitation and 2.2 for the no rehabilitation group, $p<0.001$ ) and had a higher percentage of all-cause hospital readmissions at 6 months after discharge $(31.8 \%$ vs. $23.3 \%$ for IRF and $23.7 \%$ for no rehabilitation, $\left.\mathrm{x}^{2}=14.6, p=0.001\right)$. In particular, patients receiving hospital rehabilitation had more frequently heart failure, peripheral vascular diseases, cerebrovascular disease, neurological diseases (other than dementia), and renal diseases $(p<0.001)$. Compared to the other groups, patients receiving IRF rehabilitation showed a lower incidence of cerebrovascular diseases and dementia $(p<0.001)$. Length of stay was significantly shorter in the no rehabilitation group (11.5 days) compared with the other two groups (35.2 and 34.2 days, $p<0.001)$. Patients receiving no rehabilitation showed a lower percentage of late (> $48 \mathrm{~h})$ interventions $(p=0.017)$, more reduction procedures $(p=0.022)$ and a higher incidence of previous domiciliary care $(p=0.003)$. The percentage of patients with orthopedic readmissions was not different among subgroups $\left(x^{2}=1.9, p=0.376\right)$.

The cumulative 6 -month mortality rate was $16.4 \%$, with significant differences among the groups $\left(x^{2}=\right.$ 20.7, $p<0.001)$. About one fifth $(20.8 \%)$ of patients who did not receive rehabilitation died, compared with $15.4 \%$ of patients who received IRF rehabilitation and $11.6 \%$ of patients receiving inpatient rehabilitation. The Kaplan-Meier estimates of 6-month survival differed significantly among rehabilitation pathways (log-rank test $=22.9, p<0.001$ ), (Fig. 3). The survival gap among the groups occurred mainly in the first 30 days after admission, when mortality for the two rehabilitation pathways was $0.8 \%$ (hospital), $2.1 \%$ (IRF) and $7.5 \%$ in the no rehabilitation group (log-rank test $=7.0, p=0.03$ ). Between 30 and 180 days no significant difference in mortality was found among groups $(\log$-rank $=3.5, p=0.176)$.

Multiple Cox regression (Table 2) confirmed that the rehabilitation pathway predicted a differential mortality risk also after adjusting for covariates. Specifically, compared with hospital rehabilitation, the hazard ratio was more than twofold in the no rehabilitation group and 1.66 in the IRF rehabilitation group. The covariates independently predicting a significantly higher mortality at 6 months were male gender, older age, a higher number of comorbidities, myocardial infarction, heart failure, dementia, and intervention after 2 days from the hip fracture. 
Table 1 Characteristics of the study population $(n=2208)$

\begin{tabular}{|c|c|c|c|c|c|}
\hline & $\begin{array}{l}\text { Hospital rehabilitation } \\
(N=519)\end{array}$ & $\begin{array}{l}\text { IRF rehabilitation } \\
(N=907)\end{array}$ & $\begin{array}{l}\text { No rehabilitation } \\
(N=782)\end{array}$ & $\begin{array}{l}p^{-} \\
\text {value }\end{array}$ & $\begin{array}{l}\text { Significant post-hoc } \\
\text { comparisons }\end{array}$ \\
\hline Age, mean (SD) & $83.8(7.3)$ & $83.7(7.1)$ & $84.5(7.8)$ & $0.055^{*}$ & \\
\hline N. comorbidities, mean (SD) & $3.4(2.0)$ & $2.1(2.1)$ & $2.2(2.0)$ & $\begin{array}{l}< \\
0.001^{*}\end{array}$ & hosp $>$ RF, no rehab \\
\hline Length of stay, days (SD) & $35.2(18.2)$ & $34.2(13.6)$ & $11.5(7.2)$ & $<.001^{*}$ & hosp, IRF > no rehab \\
\hline Sex, male, n (\%) & $134(25.8)$ & $211(23.3)$ & $186(23.8)$ & 0.542 & \\
\hline Myocardial infarction, n (\%) & $46(7.1)$ & $119(5.1)$ & $36(4.6)$ & 0.122 & \\
\hline Heart failure, n (\%) & $151(29.1)$ & $160(17.6)$ & $132(16.9)$ & $\begin{array}{l}< \\
0.001\end{array}$ & hosp $>$ RF, no rehab \\
\hline Peripheral vascular dis., n (\%) & $185(36.6)$ & $216(23.8)$ & $148(18.9)$ & $\begin{array}{l}< \\
0.001\end{array}$ & hosp $>\mid R F>$ no rehab \\
\hline Cerebrovascular dis., n (\%) & $102(19.7)$ & $79(8.7)$ & $127(16.2)$ & $\begin{array}{l}< \\
0.001\end{array}$ & hosp, no rehab>IRF \\
\hline Dementia, n (\%) & $112(21.6)$ & $113(12.5)$ & $170(21.7)$ & $\begin{array}{l}< \\
0.001\end{array}$ & hosp, no rehab>IRF \\
\hline Hypertension, n (\%) & $28(5.4)$ & $74(8.2)$ & $50(6.4)$ & 0.111 & \\
\hline Neurological disease, n (\%) & $219(42.2)$ & $51(5.6)$ & $76(9.7)$ & $\begin{array}{l}< \\
0.001\end{array}$ & hosp $>$ no rehab $>\mid R F$ \\
\hline Renal disease, n (\%) & 76 (14.6) & $72(7.9)$ & $69(8.8)$ & $\begin{array}{l}< \\
0.001\end{array}$ & hosp $>I R F$, no rehab \\
\hline Domiciliary care, n (\%) & $151(29.1)$ & $226(24.9)$ & $253(32.3)$ & 0.003 & no rehab $>\mid R F$ \\
\hline Intervention > 2 days, $\mathrm{n}(\%)$ & $133(25.6)$ & $226(24.9)$ & $155(19.8)$ & 0.017 & hosp, IRF > no rehab \\
\hline Hip fracture reduction, n (\%) & $272(52.4)$ & $482(52.1)$ & $461(58.9)$ & 0.022 & \\
\hline Polytrauma, n (\%) & $34(6.6)$ & $59(6.5)$ & $53(6.8)$ & 0.973 & \\
\hline Open fracture, n (\%) & $6(1.2)$ & $70(7.7)$ & $45(5.8)$ & $\begin{array}{l}< \\
0.001\end{array}$ & No rehab, IRF > hosp \\
\hline Died, n (\%) & $60(11.6)$ & $140(15.4)$ & $163(20.8)$ & $\begin{array}{l}< \\
0.001\end{array}$ & No rehab>hosp, IRF \\
\hline $\begin{array}{l}\text { Hospital readmission within } 6 \text { months, } \\
\text { all causes, } n(\%)^{\mathrm{a}}\end{array}$ & $165(32.8)$ & $211(24.3)$ & $185(25.1)$ & 0.001 & hosp>IRF, no rehab \\
\hline $\begin{array}{l}\text { Hospital readmission within } 6 \text { months, } \\
\text { orthopedic, } n(\%)^{\mathrm{a}}\end{array}$ & $16(3.2)$ & $24(2.8)$ & $30(4.1)$ & 0.337 & \\
\hline
\end{tabular}

Note: $x^{2}$ test was used, except where indicated. *Kruskal-Wallis test

${ }^{a}$ In the 2107 patients alive at the end of the episode of care

The logistic regression of all-cause readmission at 6 months from discharge (Table 3) showed that the risk of readmission was similar across rehabilitation groups. $\mathrm{Pa}-$ tients characteristics associated with a significantly higher risk of readmission were renal disease, length of stay, prior domiciliary care, dementia and number of comorbidities. Similarly, the risk of orthopedic readmissions at 6 months from discharge was unrelated to rehabilitation pathways (Table 4). Male gender and previous domiciliary care were associated with a lower risk of readmission, while length of stay, renal disease and neurological disorders other than dementia predicted a higher risk of readmission.

\section{Discussion}

This is one of the first studies to assess the effects of different rehabilitation pathways following hip fracture surgery in a universal healthcare system. The results suggest that intensive post-acute rehabilitation within the index hospital was associated with lower risk of mortality compared to other pathways, including IRF rehabilitation, which was the most frequent pathway, although this does not imply a direct causation. Learning from these data, guidelines and recommendations could boost provision of post-acute rehabilitation in the best effective and cost-effective setting, possibly with standardized protocols.

Notably, the mortality risk in patients not receiving rehabilitation was more than twofold higher compared with patients who received hospital rehabilitation and it was $66 \%$ higher in those who received IRF rehabilitation, after adjustment for patient and intervention characteristics. These results are consistent with recent literature. 


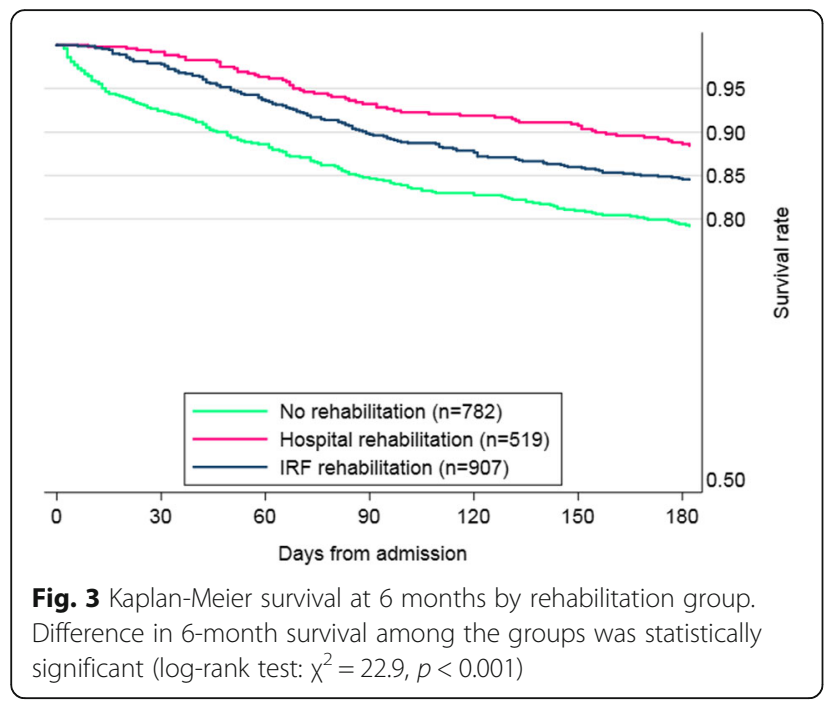

Ireland et al. reported a $60 \%$ mortality risk reduction at 3 months and $40 \%$ at 1 year after hospital discharge in patients who received hospital-based rehabilitation compared with no rehabilitation [26]. Pitzul et al. reported similar results, with a majority of patients receiving postoperative rehabilitation in IRFs [15]. A possible explanation of the lower mortality in the hospital rehabilitation group of our study is that Italian hospitals have a multidisciplinary clinical approach to patients with hip fracture, which in some facilities includes orthogeriatric services. Orthogeriatric management of patients with hip fracture proved to be effective on frail populations and has already been adopted in the regional hospitals $[14,20,27]$. Zelzter et al., showed a $2.2 \%$ reduction of 30-day mortality in patients admitted to hospitals with orthogeriatric services compared to hospitals without orthogeriatric services [28]. Another study from Sweden

Table 2 Results of the Cox regression analysis of all-cause mortality risk at 6 months from admission on rehabilitation, patient, and inpatient stay characteristics

\begin{tabular}{lll}
\hline & HR $(95 \% \mathrm{Cl})$ & $p$-value \\
\hline Hospital rehabilitation & 1 [Reference] & [Reference $]$ \\
No rehabilitation & $2.19(1.54-3.12)$ & $<0.001$ \\
IRF rehabilitation & $1.66(1.54-1.79)$ & $<0.001$ \\
Sex, male & $2.01(1.61-2.51)$ & $<0.001$ \\
Age, years & $1.08(1.05-1.11)$ & $<0.001$ \\
Number of comorbidities & $1.06(1.04-1.08)$ & $<0.001$ \\
Myocardial Infarction & $1.37(1.12-1.67)$ & 0.002 \\
Heart failure & $1.26(1.14-1.40)$ & $<0.001$ \\
Cerebrovascular disease & $0.86(0.74-0.99)$ & 0.043 \\
Dementia & $1.22(1.14-1.29)$ & $<0.001$ \\
Intervention $>2$ days & $1.27(1.22-1.33)$ & $<0.001$ \\
\hline
\end{tabular}

Abbreviations. $H R$ hazard ratio, $\mathrm{Cl}$ confidence interval
Table 3 Odds ratios of all-cause readmission within 6 months from discharge in the rehabilitation pathways, adjusting for patient and inpatient stay characteristics $(n=2107)$

\begin{tabular}{lll}
\hline & OR $(95 \% \mathrm{Cl})$ & $p$-value \\
\hline No rehabilitation & 1 (Reference) & \\
Hospital rehabilitation & $1.04(0.83-1.31)$ & 0.698 \\
IRF rehabilitation & $0.82(0.56-1.22)$ & 0.333 \\
Sex, male & $1.41(1.20-1.65)$ & 0.001 \\
Age (years) & $1.01(0.99-1.03)$ & 0.128 \\
Number of comorbidities & $1.11(1.02-1.21)$ & 0.012 \\
Dementia & $1.05(1.01-1.09)$ & 0.009 \\
Length of stay & $1.01(1.00-1.01)$ & 0.010 \\
Renal disease & $1.27(1.00-1.62)$ & 0.049 \\
Domiciliary care & $1.19(1.09-1.29)$ & $<0.001$ \\
\hline
\end{tabular}

showed that patients with hip fracture treated in hospitals with geriatric wards had lower risk of death and readmission [29]. In Italy, post-acute rehabilitation can be provided in third-level, high-specialized hospitals, as happens in $23.5 \%$ of patients of our cohort. Although our findings clearly support hospital-based rehabilitation, the healthcare system is not able to provide post-acute hospital rehabilitation to all patients. Other providers, such as IRFs, need to improve their quality of care, borrowing key aspects from the hospital organization, such as multidisciplinary teams, intensive rehabilitation and patient safety management plans.

Consistent with other studies, we found that mortality risk at 6 months was higher when surgery was performed more than 2 days after fracture, in males, and in patients with cardiovascular diseases or dementia, regardless of rehabilitation pathway [7, 30-34]. Our study found that a small proportion of patients receive surgery 2 or more days after the admission. In the last decade, Italy has successfully implemented national and local

Table 4 Odds ratios of orthopedic readmission within 6 months from discharge in the rehabilitation pathways, adjusting for patient and inpatient stay characteristics $(n=2107)$

\begin{tabular}{lll}
\hline & OR $(95 \% \mathrm{Cl})$ & $p$-value \\
\hline No rehabilitation & 1 [Reference] & [Reference] \\
Hospital rehabilitation & $0.48(0.19-1.24)$ & 0.133 \\
IRF rehabilitation & $0.45(0.20-1.04)$ & 0.062 \\
Sex, male & $0.56(0.47-0.66)$ & $<0.001$ \\
Age (years) & $0.98(0.95-1.01)$ & 0.112 \\
Length of stay (days) & $1.01(1.01-1.02)$ & $<0.001$ \\
Neurological disorders & $1.16(1.01-1.34)$ & 0.037 \\
(other than dementia) & & \\
Renal disease & $1.47(1.01-2.14)$ & 0.047 \\
Domiciliary care & $0.57(0.46-0.70)$ & $<0.001$ \\
\hline
\end{tabular}


policies aimed at reducing the time to surgery for elderly patients with hip fracture [20,35]. However, it is important to further enhance the access to timely surgery in this population, including patients 90 years of age or older, whose number is expected to significantly raise in the next future $[35,36]$. Patients with dementia deserve particular attention, given the evidence showing that these patients can benefit from intensive postoperative rehabilitation programs $[37,38]$. Seitz et al., showed that in patients with dementia, inpatient rehabilitation is associated with lower risks of long-term care admission and death compared with less intensive forms of rehabilitation, although in their population up to $40 \%$ of patients with dementia received no formal rehabilitation after hip fracture surgery [38]. Consistent with Seitz et al., our study showed that $43 \%$ of patients with dementia did not receive post-acute rehabilitation [38]. Another study by Mitchell et al., found that patients with hip fracture and dementia had higher mortality but could significantly benefit from intensive hospital rehabilitation [39]. Therefore, rehabilitation services need to be improved to ensure better quality of care for these patients. In our cohort, one third of patients did not receive rehabilitation and had significantly higher mortality than patients who underwent rehabilitation. Patients who did not receive rehabilitation showed a higher proportion of timely interventions (80\%) compared with the other groups and one third of them received domiciliary care before the hip fracture, which can be considered a proxy of frailty. Although the Cox regression model adjusted patients' survival for differences in comorbidities and demographic characteristics among groups, it is likely that other important clinical and psychosocial covariates not available account for the higher mortality of patients who were not rehabilitated.

Extending hospital rehabilitation services to all may not be feasible because of costs and lack of resources, [26] however, organizational efforts are needed to provide timely rehabilitation in adequate settings in order to increase the number of the patients receiving high-quality rehabilitation. Possible improvements could include providing the IRFs with shared orthogeriatic services and standardized rehabilitation protocols or implementing a large-scale program of intermediate care focused on rehabilitation services [27, 28]. Although intermediate care services may offer a great variety of inpatient services for an aging population, they should prove that these services are clinically effective and cost-effective [40, 41]. Further research is needed to understand which kind of post-acute rehabilitation care is more appropriate for specific subgroups of patients, for example patients with dementia or those over 85 years of age.

The different clinical pathways showed no significant differences in terms of all-cause and orthopedic readmissions. Male gender, length of stay and previous domiciliary care were the strongest predictors of all-cause readmissions. Orthopedic readmissions did not differ among subgroups. These findings may suggest that rehabilitation pathways have no impact on the long-term patients' functional status.

Implementation of effective care pathways for patients with hip fracture is still debated, [24] and it is not clear which organizational characteristics are associated with better quality of care and outcomes. In order to provide the best possible match between healthcare settings and outcomes, further high-quality research on rehabilitation services in the hospitals and in other services is needed.

Our results should be interpreted in light of several limitations. First, that the study design does not allow to interpret associations between rehabilitation pathways and patient outcomes as causal relationships. Functional outcomes are not available in the administrative databases. A 12-month follow-up would have been more appropriate to study outcomes, such as mortality, still we had a specific focus on the episode of care, in which generally rehabilitation is completed, and there is a general agreement that the time span of the episode is 6 months. Third, administrative data can be affected by variability and lack of completeness in the coding of diagnoses and procedures. However, hospital discharge records from the Emilia-Romagna region showed good accuracy of ICD-9-CM coding, partially mitigating concerns about low coding standards [42-45]. Fourth, administrative data do not include functional status, which is a key outcome in the short and the long term. Fifth, the 'no rehabilitation' group may include patients who had access to private rehabilitation. More efforts to track these patients through the care pathways are needed. Finally, the small number of readmission events limited our ability to identify the predictors of readmission in logistic regression models.

\section{Conclusion}

In conclusion, this population-based study of rehabilitation following hip surgery found that immediate rehabilitation within the index hospital was associated with lower risk of mortality. Still, we found that one-third of patients are discharged with no rehabilitation. Future programs focused on improved post-operative care should consider this evidence in planning and policy making. Innovative policies and health plans, aimed at targeting vulnerable populations, such as extremely older patients or patients with impaired cognitive functions, and implementing intermediate care models could be effective tools to expand the access to care and improve the quality of care in a growing high-need and high-cost population. 


\section{Abbreviations}

ADI: Domiciliary Care Database (Italian: Assistenza Domiciliare Integrata); ASA: Outpatient Specialty Care (Italian: Assistenza Specialistica Ambulatoriale); HDR: Hospital Discharge Record; IRF: Inpatient Rehabilitation Facility; LOS: Length of Stay

\section{Availability of data and materials}

The datasets used and/or analyzed during the current study are available from the corresponding author on reasonable request.

\section{Authors' contributions}

DT and MPF conceived the study. DT, DG, and SR analyzed and interpreted the data. DT and DG drafted the manuscript. PR, THB, LB, MR, and MPF critically reviewed the manuscript. All authors read and approved the final manuscript.

\section{Ethics approval and consent to participate}

The study was carried out in conformity with the regulations on data management of the Regional Health Authority of Emilia-Romagna, and with the Italian law on privacy (Art. 20-21, DL 196/2003) (https://www.garanteprivacy.it/web/guest/home/docweb/-/docweb-display/docweb/1311248, published in the Official Journal no. 190 of August 14, 2004) which explicitly exempts the need of ethical approval for anonymous data (Preamble \#8). Data were anonymized prior to the analysis at the regional statistical office, where each patient was assigned a unique identifier. This identifier does not allow to trace the patient's identity and other sensitive data. As anonymized administrative data are used routinely for health-care management, no specific written informed consent was needed to use patient information.

\section{Consent for publication}

$$
\text { Not applicable. }
$$

\section{Competing interests}

The authors declare that they have no competing interests.

\section{Publisher's Note}

Springer Nature remains neutral with regard to jurisdictional claims in published maps and institutional affiliations.

\section{Author details}

${ }^{1}$ Department of Biomedical and Neuromotor Sciences, University of Bologna, Via San Giacomo, 12, 40126 Bologna, Italy. ${ }^{2}$ Department of Medicine, Stanford University, 1265 Welch Road, 94305, Stanford, California, USA. ${ }^{3}$ Rizzoli Orthopedic Institute, Via Giulio Cesare Pupilli, 40138 Bologna, Italy.

Received: 19 February 2018 Accepted: 5 September 2018 Published online: 10 September 2018

\section{References}

1. Lahtinen A, Leppilahti J, Vähänikkilä H, Harmainen S, Koistinen P, Rissanen P, et al. Costs after hip fracture in independently living patients: a randomised comparison of three rehabilitation modalities. Clin Rehabil. 2017;31:672-85.

2. Cheng SY, Levy AR, Lefaivre KA, Guy P, Kuramoto L, Sobolev B. Geographic trends in incidence of hip fractures: a comprehensive literature review. Osteoporos Int. 2011;22:2575-86.

3. Zidén L, Wenestam CG, Hansson-Scherman M. A life-breaking event: early experiences of the consequences of a hip fracture for elderly people. Clin Rehabil. 2008;22:801-11.

4. Auais M, Morin S, Nadeau L, Finch L, Mayo N. Changes in frailty-related characteristics of the hip fracture population and their implications for healthcare services: evidence from Quebec, Canada. Osteoporos Int. 2013; 24:2713-24.

5. Braithwaite RS, Col NF, Wong JB. Estimating hip fracture morbidity, mortality and costs. J Am Geriatr Soc. 2003;51:364-70.

6. Shiga T, Wajima Z, Ohe Y. Is operative delay associated with increased mortality of hip fracture patients? Systematic review, meta-analysis, and meta-regression. Can J Anaesth. 2008;55:146-54.

7. Moja L, Piatti A, Pecoraro V, Ricci C, Virgili G, Salanti G, et al. Timing matters in hip fracture surgery: patients operated within 48 hours have better outcomes. A meta-analysis and meta-regression of over 190,000 patients. PLoS One. 2012;7:e46175.
8. Carretta E, Bochicchio V, Rucci P, Fabbri G, Laus M, Fantini MP. Hip fracture: effectiveness of early surgery to prevent 30-day mortality. Int Orthop. 2011; 35:419-24.

9. National Institute for Health and Care Excellence (NICE). Hip fracture: management Clinical guideline. 2011. https:/www.nice.org.uk/guidance/cg124/resources/hipfracture-management-pdf-35109449902789. Accessed 5 December 2017.

10. Scottish Intercollegiate Guidelines Network (SIGN). Management of hip fracture in older people. In: A national clinical guideline; 2009. http://www. sign.ac.uk/assets/sign111.pdf. Accessed 8 Nov 2017.

11. American Academy of Orthopedic Surgeons (AAOS). Management of hip fractures in the elderly. In: Evidence- based clinical practice guideline; 2014. https://www.aaos.org/research/guidelines/HipFxGuideline_rev.pdf. Accessed 8 Nov 2017.

12. Binder EF, Brown M, Sinacore DR, Steger-May K, Yarasheski KE, Schechtman KB. Effects of extended outpatient rehabilitation after hip fracture: a randomized controlled trial. JAMA. 2004;292:837-46.

13. Auais MA, Eilayyan O, Mayo NE. Extended exercise rehabilitation after hip fracture improves patients' physical function: a systematic review and metaanalysis. Phys Ther. 2012;92:1437-51.

14. Lahtinen A, Leppilahti J, Harmainen S, Sipilä J, Antikainen R, Seppänen $\mathrm{ML}$, et al. Geriatric and physically oriented rehabilitation improves the ability of independent living and physical rehabilitation reduces mortality: a randomised comparison of 538 patients. Clin Rehabil. 2015; 29:892-906.

15. Pitzul KB, Wodchis WP, Carter MW, Kreder HJ, Voth J, Jaglal SB. Post-acute pathways among hip fracture patients: a system-level analysis. BMC Health Serv Res. 2016;16:275.

16. Maciejewski ML, Radcliff TA, Henderson WG, Cowper Ripley D, Vogel WB,

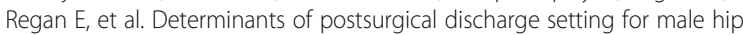
fracture patients. J Rehabil Res Dev. 2013:50:1267-76.

17. Leigheb F, Vanhaecht K, Sermeus W, Lodewijckx C, Deneckere S, Boonen S, et al. The effect of care pathways for hip fractures: a systematic overview of secondary studies. Eur J Orthop Surg Traumatol. 2013;23:737-45.

18. Organisation For Economic Co-Operation And Development (OECD). OECD Reviews of Health Care Quality: Italy 2014: Raising Standards (OECD Reviews of Health Care Systems). 2015. http://www.keepeek.com/Digital-AssetManagement/oecd/social-issues-migration-health/oecd-reviews-of-health-carequality-italy-2014_9789264225428-en\#.WRzBg|Kh2Rs. Accessed 17 May 2017.

19. France $G$, Taroni F, Donatini A. The Italian health-care system. Health Econ. 2005;14:S187-202.

20. Regione Emilia Romagna. Organizzazione dell'assistenza integrata al paziente anziano con fratture di femore - Approvazione linee guida per le Aziende Sanitarie della Regione Emilia-Romagna. 2013. http://bur.regione. emilia-romagna.it/dettaglio-inserzione?i= eb0819fb559aa40449f54cf9cf32bc39. Accessed 13 December 2017.

21. Munin MC, Begley A, Skidmore ER, Lenze EJ. Influence of rehabilitation site on hip fracture recovery in community-dwelling subjects at 6-month follow-up. Arch Phys Med Rehabil. 2006;87:1004-6.

22. Sylliaas $H$, Brovold $T$, Wyller TB, Bergland A. Progressive strength training in older patients after hip fracture: a randomised controlled trial. Age Ageing. 2011;40:221-7.

23. Eilat-Tsanani S, Tabenkin H, Kaufman B, Lavie I, Weiss Z, Apelbaum R. Rehabilitation of elderly patients in the community following surgery for hip fracture - utilization of personal and health care services. Disabil Rehabil. 2012;34:811-6.

24. Panella M, Seys D, Sermeus W, Bruyneel L, Lodewijckx C, Deneckere S, Sermon A, Nijs S, Boto P, Vanhaecht K. Minimal impact of a care pathway for geriatric hip fracture patients. Injury. 2018;49:1581-6.

25. Elixhauser A, Steiner C, Harris DR, Coffey RM. Comorbidity measures for use with administrative data. Med Care. 1998:36:8-27.

26. Ireland AW, Kelly PJ, Cumming RG. Associations between hospital-based rehabilitation for hip fracture and two-year outcomes for mortality and independent living: an Australian database study of 1,724 elderly community-dwelling patients. J Rehabil Med. 2016;48:625-31.

27. Gosch M, Hoffmann-Weltin Y, Roth T, Blauth M, Nicholas JA, Kammerlander C. Orthogeriatric co-management improves the outcome of long-term care residents with fragility fractures. Arch Orthop Trauma Surg. 2016; 136:1403-9.

28. Zeltzer J, Mitchell RJ, Toson B, Harris IA, Ahmad L, Close J. Orthogeriatric services associated with lower 30-day mortality for older patients who undergo surgery for hip fracture. Med J Aust. 2014;201:409-11. 
29. Nordström P, Michaëlsson K, Hommel A, Norrman PO, Thorngren KG, Nordström A. Geriatric rehabilitation and discharge location after hip fracture in relation to the risks of death and readmission. J Am Med Dir Assoc. 2016:17:91.e1-7.

30. Hoenig H, Rubenstein LV, Sloane R, Horner R, Kahn K. What is the role of timing in the surgical and rehabilitative care of community-dwelling older persons with acute hip fracture? Arch Intern Med. 1997;157:513-20.

31. Zuckerman JD, Skovron ML, Koval KJ, Aharonoff G, Frankel VH. Postoperative complications and mortality associated with operative delay in older patients who have a fracture of the hip. J Bone Joint Surg Am. 1995;77: 1551-6.

32. Wu CH, Liou TH, Hsiao PL, Lin YC, Chang KH. Contribution of ischemic stroke to hip fracture risk and the influence of gender difference. Arch Phys Med Rehabil. 2011;92:1987-91.

33. Tarazona-Santabalbina FJ, Belenguer-Varea Á, Rovira Daudi E, Salcedo Mahiques E, Cuesta Peredó D, Doménech-Pascual JR, et al. Severity of cognitive impairment as a prognostic factor for mortality and functional recovery of geriatric patients with hip fracture. Geriatr Gerontol Int. 2015;15: 289-95.

34. Ministero della Salute. Regolamento recante definizione degli standard qualitativi, strutturali. In: tecnologici e quantitativi relativi all'assistenza ospedaliera; 2015. http://www.gazzettaufficiale.it/eli/id/2015/06/04/ 15G00084/sg. Accessed 19 Jan 2018.

35. Boyd CM, Xue QL, Simpson CF, Guralnik JM, Fried LP. Frailty, hospitalization, and progression of disability in a cohort of disabled older women. Am J Med. 2005;118:1225-31.

36. Intiso D, Di Rienzo F, Grimaldi G, Lombardi T, Fiore P, Maruzzi G, et al. Survival and functional outcome in patients 90 years of age or older after hip fracture. Age Ageing. 2009;38:619-22.

37. Munin MC, Seligman K, Dew MA, Quear T, Skidmore ER, Gruen G, et al. Effect of rehabilitation site on functional recovery after hip fracture. Arch Phys Med Rehabil. 2005;86:367-72.

38. Seitz DP, Gill SS, Austin PC, Bell CM, Anderson GM, Gruneir A, et al. Rehabilitation of older adults with dementia after hip fracture. J Am Geriatr Soc. 2016;64:47-54.

39. Mitchell R, Harvey L, Brodaty H, Draper B, Close J. Hip fracture and the influence of dementia on health outcomes and access to hospital-based rehabilitation for older individuals. Disabil Rehabil. 2016;38:2286-95.

40. Young J, Green J, Forster A, Small N, Lowson K, Bogle S, et al. Postacute care for older people in community hospitals: a multicenter randomized controlled trial. J Am Geriatr Soc. 2007;55:1995-2002.

41. Garåsen H, Windspoll R, Johnsen R. Intermediate care at a community hospital as an alternative to prolonged general hospital care for elderly patients: a randomised controlled trial. BMC Public Health. 2007;7:68,

42. Yuen E, Louis D, Cisbani L, Rabinowitz C, De Palma R, Maio V, et al. Using administrative data to identify and stage breast cancer cases: implications for assessing quality of care. Tumori. 2011;97:428-35.

43. Tedesco D, Hernandez-Boussard T, Carretta E, Rucci P, Rolli M, Di DP a. Evaluating patient safety indicators in orthopedic surgery between Italy and the USA. Int J Qual Health Care. 2016;28:486-91.

44. Sensi L, Tedesco D, Mimmi S, Rucci P, Pisano E, Pedrini L, et al. Hospitalization rates and post-operative mortality for abdominal aortic aneurysm in Italy over the period 2000-2011. PLoS One. 2013;8:e83855.

45. Drösler SE, Romano PS, Tancredi DJ, Klazinga NS. International comparability of patient safety indicators in 15 OECD member countries: a methodological approach of adjustment by secondary diagnoses. Health Serv Res. 2012:47:275-92

Ready to submit your research? Choose BMC and benefit from:

- fast, convenient online submission

- thorough peer review by experienced researchers in your field

- rapid publication on acceptance

- support for research data, including large and complex data types

- gold Open Access which fosters wider collaboration and increased citations

- maximum visibility for your research: over $100 \mathrm{M}$ website views per year

At BMC, research is always in progress.

Learn more biomedcentral.com/submissions 